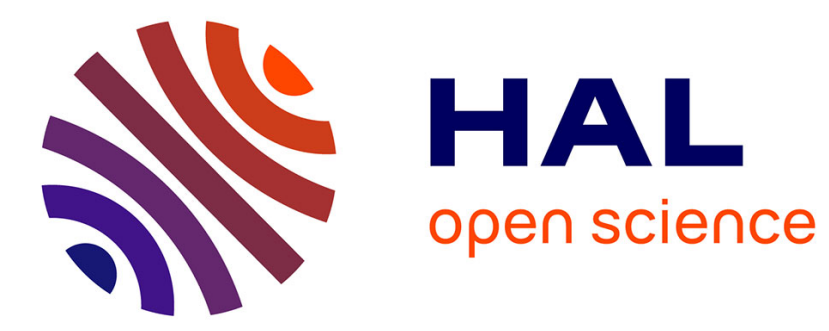

\title{
Superconductivity in ultra-thin CoSi2 epitaxial films
}

\author{
P.A. Badoz, A. Briggs, E. Rosencher, F. Arnaud d'Avitaya
}

\section{To cite this version:}

P.A. Badoz, A. Briggs, E. Rosencher, F. Arnaud d'Avitaya. Superconductivity in ultrathin CoSi2 epitaxial films. Journal de Physique Lettres, 1985, 46 (20), pp.979-983. 10.1051/jphyslet:019850046020097900 . jpa-00232927

\section{HAL Id: jpa-00232927 https://hal.science/jpa-00232927}

Submitted on 1 Jan 1985

HAL is a multi-disciplinary open access archive for the deposit and dissemination of scientific research documents, whether they are published or not. The documents may come from teaching and research institutions in France or abroad, or from public or private research centers.
L'archive ouverte pluridisciplinaire HAL, est destinée au dépôt et à la diffusion de documents scientifiques de niveau recherche, publiés ou non, émanant des établissements d'enseignement et de recherche français ou étrangers, des laboratoires publics ou privés. 
Classification

Physics Abstracts

$73.60 \mathrm{~K}-81.10 \mathrm{~J}-72.15 \mathrm{E}$

\title{
Superconductivity in ultra-thin $\mathrm{CoSi}_{\mathbf{2}}$ epitaxial films
}

\author{
P. A. Badoz $\left({ }^{1}\right)$, A. Briggs $\left({ }^{2}\right)$, E. Rosencher $\left({ }^{1}\right)$ and F. Arnaud d'Avitaya $\left({ }^{1}\right)$ \\ ( $\left.{ }^{1}\right)$ C.N.E.T., Grenoble, BP 98, 38243 Meylan Cedex, France \\ $\left({ }^{2}\right)$ C.R.T.B.T., BP 166X, 38042 Grenoble Cedex, France
}

(Reçu le 27 juin 1985, révisé le 29 août, accepté le 30 août 1985)

\begin{abstract}
Résumé. - Nous présentons les premiers résultats de supraconductivité obtenus sur des films épitaxiés de $\mathrm{CoSi}_{2}$ ultra-minces. Ces films métalliques, d'épaisseur variant de $600 \AA \AA$ à $50 \AA$ sont obtenus par épitaxie en phase solide sous ultra-vide. Ces films sont stables lors de cycles en température de $350 \mathrm{mK}$ jusqu'à la température ambiante et supraconducteurs pour des épaisseurs supérieures à $100 \AA$. Nous présentons des résultats montrant une diminution de la température critique ainsi que des variations du champ magnétique critique pour des épaisseurs décroissantes des films métalliques. De plus, nous observons un plateau intermédiaire dans la courbe de résistivité en fonction de la température pour le film de plus faible épaisseur (i.e. $100 \AA$ ). L'origine physique de ces phénomènes est brièvement discutée.
\end{abstract}

\begin{abstract}
The first results on the superconducting properties of ultra-thin epitaxial $\mathrm{CoSi}_{2}$ films are reported. The metal films are obtained by solid phase epitaxy under ultra high-vacuum conditions, with thicknesses ranging from $600 \AA$ down to $50 \AA$. These films are stable against temperature cycling from $350 \mathrm{mK}$ up to room temperature and superconducting for thicknesses down to $100 \AA$. Results showing a reduction of the transition temperature and variations of the critical magnetic field with decreasing film thicknesses are presented. Furthermore, for very low film thicknesses (i.e. $100 \AA$ ), an intermediate plateau is observed in the resistivity versus temperature curve. The physical origin of these phenomena is briefly discussed.
\end{abstract}

The epitaxial growth of metallic films on silicon is a very promising new technology due to its many applications, i.e. the Semiconductor-Metal-Semiconductor transistor [1] or the Permeable Base Transistor [2]. Thanks to ultra-high vacuum evaporation techniques, it is possible to grow crystalline metallic films of almost constant thickness (down to a few atomic monolayers) on top of silicon substrates. The epitaxial $\mathrm{CoSi}_{2} / \mathrm{Si}$ structure is currently the most extensively studied and consequently the best controlled of these systems [3]. These films, characterized by their extreme cleanliness (less than $0.01 \%$ of undesired elements) present almost ideal crystallographic and surface morphology characteristics $[4,5]$ for $\mathrm{CoSi}_{2}$ film thicknesses ranging from $200 \AA$ down to $50 \AA$. Because of these outstanding properties, $\mathrm{CoSi}_{2}$ films are good candidates for studying superconducting properties in stable ultra-thin metallic films, since bulk cobalt disilicide has already been reported superconducting at $1.22 \mathrm{~K}[6,7]$.

$3 \times 10^{15} \mathrm{~cm}^{-3}$ phosphorous doped, $\langle 111\rangle$ oriented, 2 inch Si wafers are used in this work. After a chemical cleaning described in reference [4], the wafers are loaded in a Riber 2300 Molecular Beam Epitaxy (M.B.E.) apparatus (base pressure $\sim 2 \times 10^{-10}$ torr). The cleanliness of 
the Si surfaces is achieved by an in situ progressive $900^{\circ} \mathrm{C}$ thermal annealing and checked by in situ LEED and Auger spectroscopy facilities. Cobalt is electron-beam evaporated (pressure : $10^{-7}$ torr) with the sample kept at room temperature. The deposited films are then annealed at $650{ }^{\circ} \mathrm{C}$ yielding $\mathrm{CoSi}_{2}$ film thickness ranging from $50 \AA$ up to $600 \AA$. The film thickness is determined at $\pm 10 \%$ by a quartz microbalance previously calibrated by Rutherford Back Scattering spectroscopy on test samples. The bulk $\mathrm{CoSi}_{2}$ lattice mismatch with silicon is $1.4 \%$ so that strained $\mathrm{CoSi}_{2}$ films of excellent crystallinity and uniformity are obtained for thickness up to $200 \AA$; the relaxation of strains then rapidly degrades the silicide film quality from $200 \AA$ to $600 \AA[4,5]$. Four-terminal measurements are made at room temperature, yielding the absolute room temperature resistivity, while 4 silver paste contacts are used for low temperature measurements. The samples are attached to the $\mathrm{He}^{3}$ pot of a circulating $\mathrm{He}^{3}$ refrigerator. Resistances are measured with a Barras type resistance bridge using a measuring current of $0.8 \mu \mathrm{A}$. The bridge resolution at this current level is $10^{-4} \Omega$, corresponding to a resolution of roughly $10^{-4} \mu \Omega$. cm in resistivity. Temperatures are measured with a germanium thermometer whose calibration is checked in situ against a $\mathrm{He}^{3}$ vapour pressure thermometer. "Zero " field critical temperatures are measured in a residual field of 3 gauss, and critical field values are obtained from an average for both magnetic field directions.

First, the resistivity versus temperature curves of all samples are recorded from room temperature down to $10 \mathrm{~K}$. The $\rho(T)$ curves show the expected behaviour for the resistivity of a normal metal, i.e., decrease with decreasing temperature and tend towards a residual resistivity $\rho_{0}$ at low temperature i.e. $T \sim 10 \mathrm{~K}$. The residual resistivity $\rho_{0}$ is $\sim 2.5 \mu \Omega$.cm independent of sample thicknesses down to $200 \AA$ and then increases for decreasing film thicknesses (see Table I). A mean free path $l$ is deduced from the residual resistivity data using the free electron model, as listed in table $I$.

Figure 1 shows the resistivity versus temperature curves obtained for the $\mathrm{CoSi}_{2}$ films of thicknesses 100,200 and $600 \AA$ from $1.2 \mathrm{~K}$ down to $0.75 \mathrm{~K}$. Clearly, the three films become superconducting, i.e. the resistivity of the metal films drops rapidly to zero within experimental limits. Contrarily to previous papers focused on localization effects [8], the critical temperature $T_{\mathrm{c}}$ is taken at the midpoint in the resistivity versus temperature $\rho(T)$ curve, and the transition width $\Delta T_{\mathrm{c}}$ is defined as the temperature interval between the $75 \%$ and the $25 \%$ points in the $\rho(T)$ curves. It is clearly seen in figure 1 that the critical temperature $T_{\mathrm{c}}$ and the transition width $\Delta T_{\mathrm{c}}$ decrease with decreasing film thickness. Moreover, an intermediate plateau in the $\rho(T)$

Table I. - Experimentally determined parameters for the four films described in the text; $d_{\mathrm{M}}$ is the film thickness, $T_{\mathrm{c}}$ and $\Delta T_{\mathrm{c}}$ are the critical temperature and the transition width respectively; finally $\rho_{0}$ is the residual resistivity of the layer measured at $10 \mathrm{~K}, l$ the corresponding calculated carrier mean free path and $R_{\square}$ the sheet resistance of the films.

\begin{tabular}{|c|c|c|c|c|c|}
\hline$d_{\mathrm{M}}(\AA)$ & $T_{\mathrm{c}}(\mathrm{K})$ & $\Delta T_{\mathrm{c}}(\mathrm{mK})$ & $\rho_{0}(\mu \Omega . \mathrm{cm})$ & $l(\AA)$ & $R_{\square}\left(\Omega_{\square}\right)$ \\
\hline 600 & 1.121 & 60 & 2.3 & 450 & 0.39 \\
\hline 200 & 1.047 & 30 & 2.5 & 415 & 1.25 \\
\hline 100 & 0.852 & 13 & 3.9 & 265 & 3.9 \\
\hline 50 & 0.780 & 14 & & & 12.8 \\
\hline
\end{tabular}




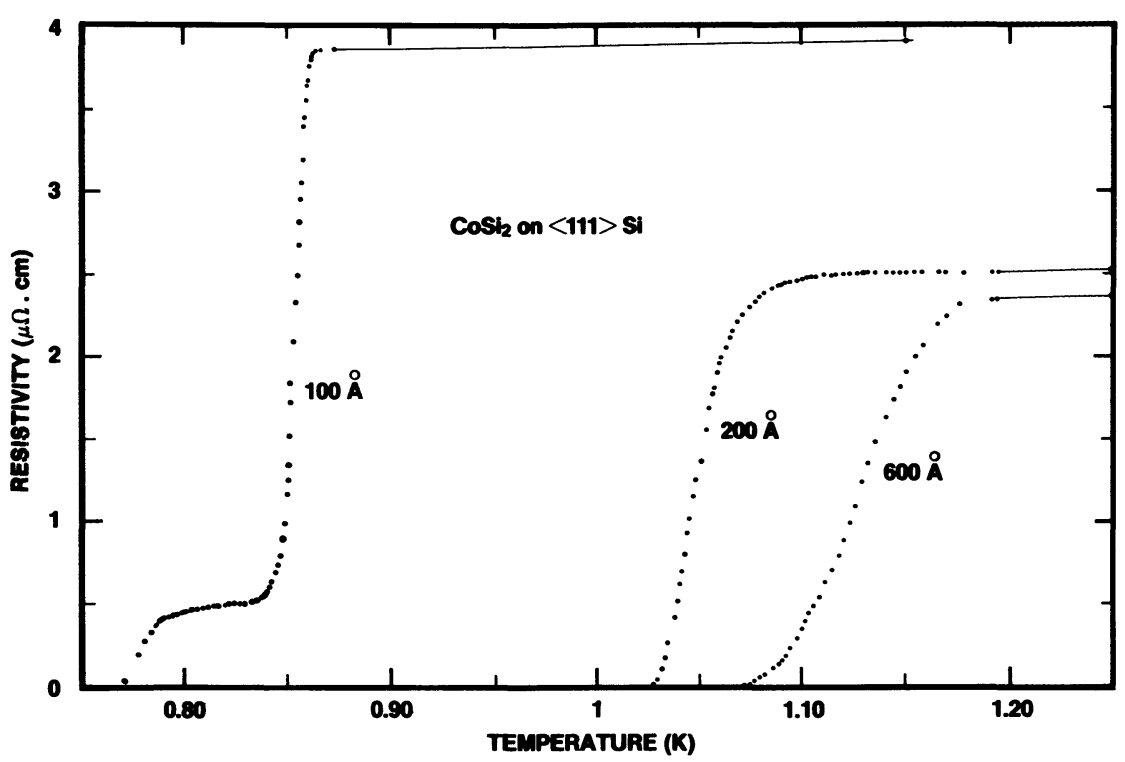

Fig. 1. - Resistivity versus temperature curves in $\mathrm{CoSi}_{2}$ epitaxial layers for three different thicknesses.

curve is observed for the $100 \AA$ thick film. The film resistivity then drops to zero below a second critical temperature $T_{\mathrm{c}}^{\prime}$. Let us finally point out that no variation in the resistivity is observed for the $50 \AA$ thick $\mathrm{CoSi}_{2}$ film from $4.2 \mathrm{~K}$ down to $350 \mathrm{mK}$. Measurements are in progress at lower temperatures. These results are summarized in table $\mathrm{I}$.

The quenching of superconductivity by a magnetic field applied normally to the $\mathrm{CoSi}_{2}$ film is then studied as a function of temperature. The critical magnetic field $H_{\mathrm{c}}$ is defined as an abrupt change in the resistivity versus magnetic field curve, recorded at stabilized temperature. Although the experimental data do not allow the determination of the type of superconductivity of these $\mathrm{CoSi}_{2}$ films, the critical magnetic fields obtained are conventionally denoted $H_{\mathrm{c}_{2}}$, the nucleation field at surfaces (since these experiments are carried out with field normal to thin films) [9]. Figure 2 then shows the $H_{c_{2}}$ versus temperature curves obtained for the three samples. It is to be noted that the $H_{\mathrm{c}_{2}}(T)$ curves for the $100 \AA$ thick sample are shown for the 2 transitions, i.e. for the two critical temperatures $T_{\mathrm{c}}$ and $T_{\mathrm{c}}^{\prime}$. For the 100 and $200 \AA$ thick samples, the $H_{\mathrm{c}_{2}}(T)$ curves are parallel, i.e. the slopes are not dependent on the film thickness, while this slope decreases for the $600 \AA$ thick sample. In the investigated temperature range, e.g. $T \sim 0.5 \mathrm{~K}, H_{\mathrm{c}_{2}}$ is clearly in the 100-200 gauss range. We can then roughly estimate a lower bound of the coherence length using $\xi^{2} \sim \phi_{0} / 2 \pi H_{c_{2}}$, where $\phi_{0}=h c / 2 e$ is the flux quantum [9]. Thus, the $\xi$ values are greater than $1300 \AA$, i.e. large compared to the film thickness.

Our residual resistivity data are very close to those obtained by J. C. Hensel et al. on similar epitaxial $\mathrm{CoSi}_{2}$ thin films $[10,11]$. These authors have shown, using the Fuchs transport theory [12], that the surface scattering in these films is essentially (but not purely) specular i.e. little loss of phase coherence is experienced by the carriers during their reflection on surfaces. In this theory, the increase in residual resistivity in the thinner 100 and $50 \AA$ thick samples is accounted for by the diffuse surface scattering component which, although weak and independent on film thickness, acts more strongly on the thinner films. Hence it seems reasonable to think that the inherent bulk resistivity and consequently the bulk critical temperature $T_{\mathrm{c}}$, which may depend strongly on $\rho_{0}$ is independent on film thickness $[13,14]$. 


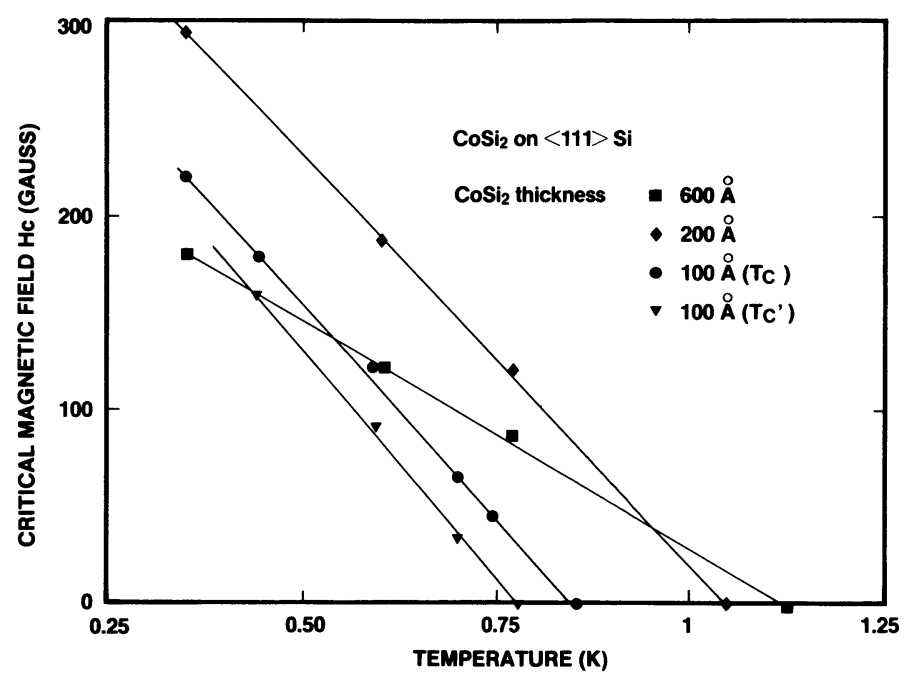

Fig. 2. - Critical magnetic field $H_{\mathrm{c}_{2}}$ versus temperature for the three $\mathrm{CoSi}_{2}$ metallic films.

An important point to be noted is that, as listed in table I, the surface resistances $R_{\square}$ of our films are much below the localization threshold $R_{\square 1} \sim \hbar / e^{2} \sim 4000 \Omega_{\square}$ [15]. This is not surprising since the $\mathrm{CoSi}_{2}$ films are crystalline (epitaxially grown) and are clearly not disordered systems. The observed reduction in $T_{\mathrm{c}}$ is related to localization or fluctuation effects. However, in view of the above remark concerning $R_{\square}$, these effects are expected to be small in our films and thus unable to explain the magnitude of the observed variations of $T_{\mathrm{c}}$.

We may think of strain effects as a possible origin of this $T_{\mathrm{c}}$ lowering. Indeed, the thin $\mathrm{CoSi}_{2}$ layers are stretched to match the silicon lattice, so that as the film thickness is increased, the strain stored in the layer increases and the system relaxes. It does so by generating dislocations in the Si bulk $[3,5]$ and tearing the $\mathrm{CoSi}_{2}$ film apart [4], thus decreasing the strain, but keeping the film still electrically continuous. The pressure dependence of $T_{\mathrm{c}}$ through the Debye temperature $\theta_{\mathrm{D}}$ and the density of states at the Fermi level has already been described in bulk metals [18]. The order of magnitude of this dependence could possibly explain the observed variations for the 3 thicker films, with $T_{\mathrm{c}}$ converging towards its reported bulk value for the low-strain $600 \AA$ thick sample. However, this cannot account for the very sharp decrease in $T_{\mathrm{c}}$ between the 100 and $50 \AA$ sample (if this film ever show a superconducting transition at $T<0.35 \mathrm{~K}$ ) as it has been shown that both 100 and $50 \AA$ thick films are similarly stretched $[4,5]$ and thus experience roughly equal negative pressure.

One may speculate that surface related or two-dimensional effects play a major rôle in the decrease of $T_{\mathrm{c}}$ with film thickness; for instance, the diffuse surface scattering mechanism which plays a minor rôle in the 600 and $200 \AA$ thick films and takes a more active part in the two thinner films may be of importance in the comprehension of the phenomenon. Studies are in progress for a better understanding of the problems involved here.

As far as the plateau in the $\rho(T)$ versus temperature curve of the $100 \AA$ film is concerned, this effect could be related to the growing influence of surface roughness. Indeed, such plateaus have already been reported in granular films and two dimensional arrays of Josephson junctions, and have been interpreted as superconducting regions weakly coupled through normal regions [19]. This could apply to our system if we assume that, for thin enough samples, fluctuations in the layer thickness define superconductive $\mathrm{CoSi}_{2}$ islands separated by thinner (and consequently in the normal state at the measuring temperature) metal patches. 
In conclusion, we have shown that $\mathrm{CoSi}_{2}$ films epitaxially grown on top of $\mathrm{Si}$ substrates are superconducting for film thickness down to $100 \AA$. Variations in critical temperature $T_{\mathrm{c}}$, $\operatorname{transi}$ tion width $\Delta T_{\mathrm{c}}$ and critical magnetic field $H_{\mathrm{c}_{2}}$ are revealed. The origin of the decrease in $T_{\mathrm{c}}$ with decreasing film thickness is discussed, noting that the low $R_{\square}$ of our films seems to exclude any localization effects.

\section{Acknowledgments.}

The authors are deeply indebted to Prof. M. Cyrot from CNRS and to Prof. J. C. Pfister from CNET for many fruitful discussions.

\section{References}

[1] Rosencher, E., Delage, S., Campidelli, Y. and Arnaud d’Avitaya, F., Electron. Lett. 20 (1984) 762.

[2] Ishibashi, K. and Furukawa, S., IEDM Techn. Dig. (1984) 868.

[3] See, for instance, Tung, R. T., Poate, J. M., Bean, J. C., Gibson, J. M. and Jacobson, D. C., Thin Solid Films 93 (1982) 77.

[4] Arnaud d'Avitaya, F., Delage, S., Rosencher, E. and Derrien, J., J. Vac. Sci. Technol. B 3 (1985) 770.

[5] D'Anterroches, C. and Arnaud d'Avitaya, F., Thin Solid Films, to be published.

[6] Roberts, B. W., J. Phys. Chem. Ref. Data 5 (3) (1976) 581.

[7] Rosencher, E., Badoz, P. A., Briggs, A., Campidelli, Y. and Arnaud d'Avitaya, F., Proceedings of the First International Conference on Silicon Molecular Beam Epitaxy, to be published.

[8] Hebard, A. F. and Paalanen, M. A., Phys. Rev. Lett. 54 (1985) 2155.

[9] TINkHAM, M., Introduction to Superconductivity (McGraw-Hill, New York) 1975.

[10] Hensel, J. C., Tung, R. T., Poate, J. M. and Unterwald, F. C., Appl. Phys. Lett. 44 (1984) 913.

[11] Hensel, J. C., Tung, R. T., Poate, J. M. and Unterwald, F. C., Phys. Rev. Lett. 54 (1985) 1840.

[12] Fuchs, K., Proc. Cambridge Philos. Soc. 34 (1938) 100.

[13] Anderson, P. W., Muttalib, K. A. and Ramakrishnan, T. V., Phys. Rev. B 28 (1983) 117.

[14] Graybeal, J. M. and Beasley, M. R., Phys. Rev. B 29 (1984) 4167.

[15] We do not observe any increase in the film resistivity as $T$ decreases, an expected behaviour in weak localization [16], previously reported in narrow Al films [17].

[16] Abrahams, E., Anderson, P. W., Licciardello, D. C. and Ramakrishnan, T. V., Phys. Rev. Lett. 42 (1979) 673.

[17] Borodin, D. V., Latyshev, Yu. I. and NaD', F. Ya., Pis'ma Zh. Eksp. Teor. Fiz. 35 (1982) 201 ; JETP Lett. 35 (1982) 249.

[18] Meservey, R. and Schwartz, B. B., Superconductivity Ed. R. D. Parks (Marcel Dekker, Inc., New York) 1969, p. 169.

[19] MooIJ, J. E., Lecture notes for the NATO advanced study institute on Percolation, Localization and Superconductivity, les Arcs, France (1983). 